\title{
Is Semicompatibilism Unstable?
}

\author{
Taylor W. Cyr \\ University of California, Riverside \\ BIBLID [0873-626X (2017) 45; pp. 245-264] \\ DOI: $10.1515 /$ disp-2017-0006
}

\begin{abstract}
Recently, John Maier has developed a unified account of various agentive modalities (such as general abilities, potentialities, and skills). According to him, however, adopting the account provides an alternative framework for thinking about free will and moral responsibility, one that reveals an unacceptable instability in semicompatibilism (the view that the freedom required for moral responsibility is compatible with determinism even if the freedom to do otherwise is not). In this paper, I argue that Maier is mistaken about the implications of his account and sketch a semicompatibilist proposal that can, without countenancing any instability, accept Maier's unified account of the agentive modalities.
\end{abstract}

\section{Keywords}

Ability, John Martin Fischer, John Maier, option, semicompatibilism.

\section{Introduction}

Semicompatibilism is the view that the freedom required for moral responsibility is compatible with causal determinism even if the ability (or freedom) to do otherwise is not. According to John Martin Fischer, who both introduced the term semicompatibilism and has labored much in defense of the view, one appealing feature of the view is that it does not leave our status as morally responsible agents - and thus our being appropriate candidates for the reactive attitudes (such as resentment and gratitude), and perhaps even our being persons, in some sense - to depend on whether or not our world is causally deterministic. ${ }^{1}$ As Fischer puts it, semicompatibilism maintains 'that our basic status as distinctively free and morally responsible agents

${ }^{1}$ See Fischer 1994 for more on semicompatibilism and what is at stake in debates about freedom and moral responsibility.

Disputatio, Vol. IX, No. 45, October 2017

Received: 27/07/2017 Accepted: 02/11/2017

(C) 2017 Taylor W. Cyr. Creative Commons Attribution-NonCommercial-NoDerivs 3.0 License 
should not depend on the arcane ruminations - and deliverances of the theoretical physicists and cosmologists' (Fischer 2006: 5). Libertarianism, by contrast - which is the view that, though free will is incompatible with causal determinism, at least some of us have free will-implies that our moral responsibility 'hangs by a thread' in virtue of its lacking resilience to potential deliverances of the sciences (such as that the thesis of causal determinism is true). At least in comparison to libertarianism, then, semicompatibilism appears a rather stable position concerning our freedom and moral responsibility.

Recently, however, John Maier (2015) has developed an account of what he calls the 'agentive modalities' that, on his view, reveals a certain instability in semicompatibilism. Maier's primary aim is to develop a unified account of the various modal aspects of agency (including, as we will see, agents' general abilities, potentialities, and skills) according to which all such aspects can be understood in terms of the decision-theoretic notion of agents' options. But Maier also claims that adopting his account of the agentive modalities provides an alternative framework for thinking about free will and moral responsibility. This framework, he thinks, constrains the possible (viable) positions in the debate; in particular, Maier thinks that the framework reveals an unacceptable instability in semicompatibilism and thus that it is not a viable position. So much, it would seem, for semicompatibilism's stability.

On my view, however, while Maier's account of the agentive modalities is an interesting and (in my view) promising one, he is nevertheless mistaken about the implications of the account. In addition to presenting certain problems for the proposed framework (for thinking about free will and moral responsibility), I argue that it is a mistake to think that the framework reveals any instability in semicompatibilism. In defending semicompatibilism against the charge of instability, I will call attention to an ambiguity in Maier's notion of 'option' - the notion on which the other agential modalities are built - and argue that neither disambiguation reveals any problematic instability in semicompatibilism. On the disambiguation that would allow the charge of 'instability' to apply to semicompatibilism, the instability would be too weak to be problematic, and indeed the charge would apply more generally, even to Maier's own account. 
On the second disambiguation of 'option', however, the charge of instability fails to apply to semicompatibilism. In addition to challenging Maier's application of his account to debates about freedom and responsibility, then, my project here helps to clarify the notion of 'option' and the nature of the stability of the agentive modalities.

In what follows, I begin by outlining the basics of semicompatibilism, using Fischer's sophisticated version as a model. I proceed by summarizing Maier's account of the agentive modalities, explaining how his analyses of various agentive modalities are built around the notion of agents' options. I then explain how Maier takes his account to provide an alternative framework for thinking about freedom and moral responsibility. Next, I give two objections to Maier's proposed framework. Lastly, I argue that, even if we adopt the proposed framework, semicompatibilists can accept Maier's account of the agentive modalities without countenancing any instability. To show this, I will propose an account of options - one that is semicompatibilist-friendly and that involves no unacceptable instability — which can unify the very same agentive modalities as does Maier's account.

\section{Semicompatibilism: the basics}

Some semicompatibilists (including Fischer) are motivated to be semicompatibilists (rather than, say, classical compatibilists, who think that free will requires the freedom to do otherwise) by arguments like the following:

If determinism is true, then our actions are entailed by the conjunction of the laws of nature and propositions about the state of the world in the remote past. If an agent actually performs some action $\mathrm{X}$ at time $\mathrm{T}$ in a deterministic world $\mathrm{w}$, then that agent's having had the freedom to do otherwise than $\mathrm{X}$ at $\mathrm{T}$ in $\mathrm{w}$ required that the agent either (1) was able to violate a law of nature or (2) was able to bring it about that the state of the world in the remote past was different than it actually was. Since no agent has the abilities mentioned in (1) and (2), it follows that no one has the freedom to do otherwise than what they actually do, if determinism is true. ${ }^{2}$

2 This argument is a member of a family of arguments often called the Consequence Argument. See van Inwagen (1983) for an extensive discussion of this family 
Typically, proponents of this argument are incompatibilists, but notice that, even if this argument is sound, it would only show that classical compatibilism (which says that determinism is compatible with the freedom to do otherwise) is false. Semicompatibilists maintain instead that one can possess the freedom relevant to moral responsibility even in cases in which one lacks the freedom to do otherwise, and semicompatibilists typically take the so-called 'Frankfurt-style cases' (which I will discuss later on) to show that there can be cases in which one lacks the freedom to do otherwise and yet is morally responsible.

The challenge for semicompatibilists, however, is to explain why moral responsibility is undermined in some cases of lacking the freedom to do otherwise (such as in extreme cases of coercion or manipulation) but would not be undermined if causal determinism were true and did in fact preclude the freedom to do otherwise. This is precisely what Fischer and coauthor Mark Ravizza attempt to do in developing their account of 'guidance control. ${ }^{3}$ According to Fischer and Ravizza, an agent exercises guidance control in performing an action if and only if that action issues from the agent's own moderately reasons-responsive mechanism. ${ }^{4}$ In other words, guidance control has two parts: first, the agent's operative mechanism must be reasons-responsive; second, that mechanism must be the agent's own. A mechanism is moderately reasons-responsive just in case it is both moderately receptive to reasons and at least weakly reactive to reasons. Moderate receptivity to reasons requires that the mechanism display an understandable pattern of recognizing reasons for/against the action (at least some of which must be moral reasons) in a range of possible worlds with the same laws of nature. Weak reactivity to reasons requires that, in some possible world (with the same laws of nature) in which the mechanism recognizes a sufficient reason to do otherwise, the mechanism acts in accordance with that sufficient reason (Fischer and Ravizza 1998: 69-82). Ownership

of arguments. A very similar argument can be constructed replaces determinism with the existence of an essentially omniscient and sempiternal God.

${ }^{3}$ See Fischer and Ravizza 1998 for the full account.

${ }^{4}$ The account of guidance control extends to omissions as well, but, to keep things simple, I will focus on actions in this paper. 
of a mechanism, on the other hand, requires taking responsibility for the mechanism, which involves three major ingredients: first, the agent must see herself as an agent whose actions are efficacious in the world; second, the agent must accept that she is a fair target of the reactive attitudes as a result of how she exercises her agency in certain contexts; and third, the agent's view of herself specified in the previous ingredients must be based, in an appropriate way, on the evidence (Fischer and Ravizza 1998: 210-213). Now, according to Fischer and Ravizza, it is possible for an agent to satisfy these conditions in a deterministic world, even if the agent lacks the freedom to do otherwise than what she actually does, but at least one of these conditions will fail to be satisfied in the cases in which moral responsibility is undermined by a lack of freedom to do otherwise (such as extreme cases of coercion or manipulation).

With the basics of a semicompatibilist framework on the table, we can now turn to Maier's account of the agentive modalities.

\section{Maier's agentive modalities}

When asking whether or not some agent can perform some action, there are various candidates for what aspect of that person's agency is relevant to the question. As Maier notes, we might be asking, for example, about the agent's abilities, or about her potentialities, or about her skills. ${ }^{5}$ Despite the fact that these aspects of agency just mentioned are themselves a motley set, Maier provides a novel account of these aspects of agency according to which these aspects are part of a unified family. On his account, each aspect of agency mentioned above can be understood modally (hence the name agentive modalities), and each aspect can be analyzed in terms of the primitive, decision-theoretic notion of agents' options. Since our concern here is primarily with the application of Maier's account to debates about free will and moral responsibility, not every detail of the account is relevant. Still, a summary of Maier's notion of an option and of how the other agentive modalities are built out of that notion will be crucial for understanding the putative implications of the account, as

\footnotetext{
${ }^{5}$ Maier (2015) uses these three examples throughout the paper and provides an account of each in terms of agents' options.
} 
well as my response to them.

First, let us consider the notion of an option. According to Maier, when we ask whether a certain agent, Rachel, can speak Mandarin, 'We may be asking what she is now able to do, what she is free to do, what acts are available to her, or what is in her power to do. These phrases pick out the agentive modality on which I will focus here: they pick out Rachel's options' (Maier 2015: 119-120). Despite the disparity of these phrases, Maier claims that we can get an intuitive grasp of options by considering their role in ordinary choice situations:

Why think that, under this linguistic diversity, there is metaphysical unity? That is, why think that there is a single relation picked out by these various phrases? The way to answer these questions... is by appeal to the role of this notion [of options] in choice situations. When we describe a choice situation - either in folk psychology or in the precisification of folk psychology given by decision theory — we speak of an agent who has several options available to her, among which she must decide. (Maier 2015: 120)

On Maier's view, we can understand questions such as whether Rachel is now able to speak Mandarin by considering whether Rachel's now speaking Mandarin is an option for her in some choice situation - an option available to her that she might decide to take. Options are the sorts of things that can be objects of our deliberations (indeed, these are what we face in choice situations), but we have many options that we do not in fact deliberate about. ${ }^{6}$ A few minutes ago I had the option of doing some jumping-jacks, but at the time the possibility did not even occur to me and thus did not appear in my process of deliberation. Finally, options play a role, Maier claims, in questions about rationality and morality; agents confront a range of options and

\footnotetext{
${ }^{6}$ Maier makes this explicit in a footnote: 'Of course, in framing a choice situation we can and often do ignore many of the options that are available. There are many sentences that I am now in a position to write, but only a few of them are salient in the deliberative context in which I find myself. But we may also explicitly lift such restrictions, and ask what is an option for me simpliciter. The range of options thus arrived at will be significantly broader than that which is relevant to ordinary choice situations...It is this unrestricted representation of an agent's choice situation that corresponds to what her options are.' (Maier 2015: 120, n. 9)
} 
must decide which option to take. ${ }^{7}$

As mentioned above, Maier provides analyses of various modal aspects of agency - including general abilities, potentialities, and skills - in terms of agents' options. Given that we will return to this unified account of the agentive modalities at the end of the paper, it will be helpful to summarize the account here. Let us begin with his analysis of agents' general abilities. On Maier's account (where ' $\mathrm{S}$ ' is an agent and ' $\mathrm{A}$ ' is an action):

Ability: $\mathrm{S}$ has the general ability to $\mathrm{A}$ iff $\mathrm{S}$ has, in a suitable proportion of similar circumstances, the option of Aing. (Maier 2015: 127)

There are two crucial features of this account. First, someone can have the general ability to do something even if it is not now an option for her. ${ }^{8}$ To use an example from Maier, it is possible for Rachel to have the general ability to speak Mandarin even if right now, because she is under the effects of novocaine, Rachel does not have the option of speaking Mandarin. The second crucial feature of the account is that general abilities are not flukes; they require that a certain option be available in a suitable proportion of similar circumstances. I might happen to have the option of sinking a free-throw even if, poor basketball-player that I am, I lack the general ability to sink a free-throw (since the option is not available in a suitable proportion of similar circumstances). Importantly, then, S's having A as an option in certain circumstances is neither necessary nor sufficient for $\mathrm{S}$ to have the general ability to A.

With the account of general abilities on the table, it is easy to see how Maier aims for his account to capture potentialities and skills. Let us begin with the former:

Potentiality: S has the potentiality to A just in case there is a certain series of actions, each of which is an option for $\mathrm{S}$, such that if $\mathrm{S}$ were to perform those actions then $S$ would have the general ability to A. (Maier 2015: 131)

\footnotetext{
${ }^{7}$ There are other important features of Maier's account of options (such as that they are indispensable and determinate), but this much will suffice for present purposes.

${ }^{8}$ For $\mathrm{S}$ to have the option to $\mathrm{A}$ in a similar circumstance is for there to be a possible world, relevantly similar to the actual world, in which S has the option to A (see Maier 2015: 125-126). Thus, Maier's account of general abilities is a modal one.
} 
A potentiality, as Maier understands it, is a potential to acquire some general ability. For example, I have the potentiality to speak Mandarin just in case I have the option of going to a Mandarin class, the option of practicing Mandarin, etc., at the end of which series I would have the general ability to speak Mandarin. Given this account of potentialities, there are many things that I (now) lack the general ability to do but that are nevertheless potentialities for me. Skills, on the other hand, are a narrower class within the sphere of general abilities:

Skill: $\mathrm{S}$ has the skill to A just in case $\mathrm{S}$ has the general ability to A partly in virtue of what she knows. (Maier 2015: 131)

A fluent speaker of both English and Mandarin, for example, has the skill to translate a sentence from English to Mandarin just in case she has the general ability to translate the sentence and has that general ability partly because of what she knows (about the languages, in this case). ${ }^{9}$

\section{Implications for the free will debate}

While Maier's main goal is to develop an integrated account of the agentive modalities, according to which all such modalities are reducible to one particular modality (agents' options), he also suggests an alternative framework for thinking about whether or not free will is compatible with determinism. Here is Maier's suggestion:

The question is the familiar one of whether the freedom of agents is compatible with the thesis of determinism. The foregoing discussion does not settle this question, though it does offer one way of framing it. On the present conception, the question is simply a question about the nature of options, and their relation to nomic possibility. Can it be the case that $\mathrm{A}$ is an option for $\mathrm{S}$ though it is not possible, relative to the laws and the past, that $\mathrm{S}$ does $\mathrm{A}$ ? If one answers this question in the affirmative, then one is a compatibilist in the relevant sense; if in the negative, then one is an incompatibilist. Nothing said thus far demands one answer or the other to this question. (Maier 2015: 132-133)

\footnotetext{
${ }^{9}$ As Maier mentions in a footnote (2015: 131, n. 27), the 'in virtue of' in the account of skills is meant to express a grounding relationship according to which the agent's ability is (at least partly) grounded in the agent's knowledge.
} 
Although the account does not settle the truth of in/compatibilism, Maier's account of options, he thinks, provides an alternative way of framing the debate. Keeping in mind that agents' options are what feature in choice situations, in which agents must select which option to take, incompatibilists deny that agents in deterministic worlds have multiple options (i.e., at least one option to do otherwise), whereas compatibilists grant that agents can have various options in deterministic worlds.

Additionally, Maier thinks, adopting this new framework requires that a certain position in the debate be given up:

The foregoing discussion, if correct, may foreclose some possibilities in this debate. Here is one. Some authors have suggested that even if agents lack options they nonetheless enjoy certain more general powers in virtue of which it can be just to blame them. [footnote omitted $^{10}$ ] If the analysis defended above is correct, then this sort of position may not be a stable one. For disjunctive approaches to the question of compatibilism - on which determinism would threaten some agentive modalities but not others - seem to be threatened by the present approach, on which the agentive modalities constitute an integrated whole that is not divisible in the way envisaged. (Maier 2015: 133)

According to Maier, semicompatibilism - according to which an agent can be free (in the sense relevant to moral responsibility) to do some action without having any option of doing otherwise- is an unstable position. For, on this view, determinism may well preclude agents' having options to do otherwise than what they actually do without precluding agents' being responsive to reasons in such a way that they can be free (in the sense relevant to moral responsibility). Maier's worry for semicompatibilism is that, once we analyze reasons-responsiveness in terms of agents' options (such that these aspects of agency constitute an integrated whole), the view will be forced to accept that determinism precludes reasons-responsiveness as well as options of doing otherwise. ${ }^{11}$

${ }^{10}$ In the footnote omitted, Maier references Fischer and Ravizza (1998) and Wallace (1994), making it clear that he has semicompatibilism in mind as his target.

${ }^{11}$ It is worth noting briefly that Maier's criticism of semicompatibilism, if sound, would also apply to the views of the so-called 'new dispositionalists' (Smith 2003; Fara 2008; and Vihvelin 2013), since they posit that what is im- 
On my view, Maier is mistaken about both of these supposed implications of the account. I will first show that there are two major problems for the framework itself. I will then argue that, even setting aside the problems for the framework, it does not follow that there is any instability in semicompatibilism.

\section{Problems for the framework}

One problem for Maier's proposed framework (for thinking about free will and whether or not it is compatible with determinism) is that it simply assumes, without argument, that an agent's free will requires that she have alternative options, holding fixed the laws of nature. Again, according to the framework Maier suggests, incompatibilists say that determinism precludes our ever having the option to do otherwise than we do, whereas compatibilists say that determinism does not preclude our having the option to do otherwise. On either view, therefore, free will requires that we have alternative options - options to do otherwise than what we actually do. Maier does not argue for the claim that free will requires having the option to do otherwise but rather assumes it in constructing his framework for distinguishing in/compatibilists.

But this assumption is highly contentious, as the literature on socalled 'Frankfurt-style cases' shows. Named after Harry Frankfurt, because of his influential discussion of such cases in Frankfurt 1969, Frankfurt-style cases aim to show that an agent can be morally responsible for doing some action even though she lacked the ability to do otherwise. The structure is simple enough: an agent Jones performs an action (such as voting for a Republican!) on his own, and for his own reasons, and is seemingly morally responsible for doing so, despite his being monitored by another agent (typically some nefarious neurosurgeon) Black, who would intervene and force Jones to do the action if Jones showed any sign that he would do otherwise. Even

portant to freedom is having something like the general ability to do otherwise, which does not itself require having the option of doing otherwise on a particular occasion - like on Maier's own account of general abilities, an agent's having an option in certain circumstances is neither necessary nor sufficient for having the general ability. We can set this point aside, though. 
if Jones thinks he has the option of doing otherwise, it turns out that Black's presence precludes his having the actual option of doing otherwise. Many are convinced by such cases that agents can be morally responsible for doing some action despite lacking any option of doing otherwise. The assumption that free will, or the freedom relevant to moral responsibility, requires having the option of doing otherwise is, therefore, a contentious assumption. And given that this assumption is contentious, it will not do simply to assume it at the outset when presenting a framework for thinking about the debate.

A second problem for Maier's proposed framework is that it makes incorrect prescriptions concerning whether certain positions count as compatibilist or incompatibilist positions. Again, according to Maier's suggestion, a position counts as an incompatibilist position just in case it says that determinism would preclude our having alternative options. On this view, however, certain positions that are clearly compatibilist positions get counted as incompatibilist positions. One example is semicompatibilism; semicompatibilists believe that even if determinism precludes our having alternative options, free will (or the freedom relevant to moral responsibility) is nevertheless compatible with determinism. Perhaps, though, Maier would be fine with this result since he thinks that the framework forecloses this position as an option anyway.

Another example, however, is what has been called 'Humean compatibilism. ${ }^{12}$ According to Humean compatibilism, free will is compatible with determinism because there is a sense in which the laws of nature are 'up to us.' This brand of compatibilism relies on a Humean position on the laws of nature (as opposed to a 'governing' view), according to which the laws of a particular world are something like contingent regularities (or uniformities) of that world. Since the pertinent regularities depend on the world as whole, including such things as how agents actually behave in the world, Humean compatibilists maintain that we can be free to do otherwise than we do in deterministic worlds and thus that free will is compatible with determinism.

According to Maier's proposal, however, Humean compatibilism counts as an incompatibilist position. According to Humean

${ }^{12}$ For a discussion of this position, see Beebee and Mele 2002. 
compatibilism, if determinism is true and we hold fixed the past and the laws, then one does not have the option of doing otherwise than what one does, and thus the view would count as an incompatibilist one on Maier's framework. The Humean compatibilist will balk at this characterization, though, since having that sort of option to do otherwise is not relevant to the Humean compatiblist; since the laws are dependent on what actually happens, there is no need to hold them fixed when considering what an agent's options are. So Maier's proposed framework makes incorrect prescriptions concerning whether certain positions count as in/compatibilist positions.

\section{The stability of semicompatibilism}

Even if Maier's proposed framework could avoid the problems raised in the previous section, it would not follow that semicompatibilism suffers any instability. Since semicompatibilism is committed to the possibility that 'even if agents lack options they nonetheless enjoy certain more general powers in virtue of which it can be just to blame them' (Maier 2015: 133), the view seems committed to the rejection of any unified account of the agentive modalities and thus to a certain instability - some agentive modalities (options) would be precluded by causal determinism, for example, but others (reasonsresponsiveness) would not. Perhaps Maier would even charge semicompatibilism with letting certain of the agentive modalities 'hang by a thread.'

But, as I will argue in the remainder of this paper, the truth of Maier's account would not entail any instability in semicompatibilism. To do this, I will begin by highlighting an ambiguity in Maier's notion of 'option' and argue that neither disambiguation reveals any problematic instability in semicompatibilism. On the disambiguation that would allow the charge of 'instability' to apply to semicompatibilism, the instability would be too weak to be problematic, and indeed the charge would apply more generally, even to Maier's own account. On the second disambiguation, however, the charge of instability fails to apply to semicompatibilism. In arguing for this latter claim, I will propose an account of options - one that is semicompatibilist-friendly and that involves no unacceptable instability - which can unify the very same agentive modalities as does Maier's account. 
Maier thinks that the notion of an option is intuitive, given its role in choice situations. But Maier makes some claims about options that should cast doubt on the intuitiveness of the notion and that, more importantly (for my purposes), give rise to an ambiguity of 'option'. First, when contrasting options with general abilities, Maier says that the distinction tracks the typical distinction between 'specific abilities' and 'general abilities' (Maier 2015: 123). Second, Maier remains neutral on whether physical possibility is a necessary condition for being an option (Maier 2015: 120, n. 8). But these two claims are in tension with each other, if not inconsistent, and they suggest that there is an ambiguity of 'option'. One disambiguation has it that an option is anything that can happen to/by an agent-i.e., anything that is possible (though not necessarily merely physically possible) for an agent..$^{13}$ On this disambiguation, winning the lottery is an option for me just as typing this sentence is an option for me. The second disambiguation of 'option' has it that an option is anything that an agent has it in her power to bring about. This, I think, is what most philosophers of action have in mind when they talk about specific abilities. In fact, in his entry on 'Abilities' in the Stanford Encyclopedia of Philosophy, Maier says:

Consider a well-trained tennis player equipped with ball and racquet, standing at the service line. There is, as it were, nothing standing between her and a serve: every prerequisite for her serving has been met. Such an agent is in a position to serve, or has serving as an option. Let us say that such an agent has the specific ability to serve. (Maier 2014)

A well-trained player in these circumstances has the option (in the present sense) of serving because 'there is nothing standing between her and the serve'. When I am at the gas station, however, I lack the option (in the present sense) of winning the lottery because there is something between me and winning the lottery, namely a very high probability that I will fail. ${ }^{14}$ (Similarly, even if I now have the option

\footnotetext{
${ }^{13}$ I use the expression 'can happen to/by the agent' to indicate that, on this disambiguation of 'options', some of an agent's options are not actions done by the agent but rather are mere happenings that involve the agent. It is an option for me, on this disambiguation of 'option', that I have a seizure and spill my coffee, but this wouldn't be an action of mine.
}

${ }^{14}$ Maier uses language similar to this when he says: 'There are at least two 
of landing a tennis serve, I do not have the option of landing it within a particular square-foot plot within the box-I'm not that good at tennis!)

Having distinguished between these two disambiguations of 'option', we can present a dilemma to Maier: either we take the first disambiguation, or we take the second. If we take the second, then we can understand options either as being what I will call 'contrastive' or as being 'non-contrastive' - that is: either (1) having an option to A requires simultaneously having the option of doing something else instead (or at least refraining from Aing), or (2) having an option to A does not require simultaneously having the option of doing something else instead. Maier has not argued for either of these accounts of options, but his argument against semicompatibilism relies on (1). This is problematic, however, because the assumption of (1) begs the question against the semicompatibilist. ${ }^{15}$ In a moment, I will present a version of (2) that is consistent with semicompatibilism (and with its being stable) and that can unify the same agentive modalities as Maier's account does, demonstrating that it is possible for semicompatibilists to accept this disambiguation of 'option' and yet to avoid any instability.

If we take the first disambiguation of 'option', however-i.e., the one which has it that an option is anything that can happen to/ by an agent - it will be clear that there is no instability in semicompatibilism. Here's why. Suppose our world is deterministic and that $S$ satisfies semicompatibilist conditions on free action (such as Fischer and Ravizza's conditions on guidance control) in doing A. It follows from the fact that $\mathrm{S}$ did $\mathrm{A}$ (on the present disambiguation of 'option') that A was an option for S. On this view, then, not only are certain powers (like moderate reasons-responsiveness) compatible

ways in which a given agent may be able to perform a certain action. It may be now in her power to perform that action: there is, as it were, nothing between her and the deed. This corresponds to what I have been calling options' (Maier 2015: 123).

${ }^{15}$ This point is related to the one I made in connection with Frankfurt-style cases in section 5. It should not be assumed, without argument, that options to do otherwise in this 'contrastive' sense are necessary for freedom and responsibility. (Perhaps some sort of merely 'epistemic' contrastive options are necessary, such that an agent must be able to deliberate among various options, but, of course, no one thinks that such options would be precluded by determinism.) 
with determinism, but so are options. A semicompatibilist account would not have to say that any of the agentive modalities that Maier considers would be precluded by determinism, so semicompatibilism would not lack stability.

One might nevertheless worry that it is consistent with a semicompatibilist account that options to do otherwise would be precluded by determinism, and perhaps this constitutes an instability of the position. But I do not see how this thin a notion could be considered an instability. On Maier's own account, options are neither necessary nor sufficient for general abilities, so I could lose the option of Aing without losing the general ability to A. This does not seem to constitute an instability in Maier's account, so why should the fact that determinism would close off some particular options (rather than, say, closing off an entire agentive modality, like options in general) introduce an instability? If Maier thinks that this is the problem for semicompatibilism, we are owed a fuller explanation. ${ }^{16}$

The aim of the remainder of this paper is to present a semicompatibilist notion of an option - one that corresponds to the second disambiguation of Maier's notion of 'option' - and to show that it can be used to unify the same agentive modalities as Maier's account does. ${ }^{17}$ On this understanding of an option, having an option to $\mathrm{A}$ is

${ }^{16}$ In a way, I will be arguing in the remainder of the paper that a different understanding of options has the same result - some options would be precluded by determinism, but not options in general - so there is no threat to the agentive modalities on this understanding of options. I think this is crucial to seeing why Maier's challenge to semicompatibilism fails. Recall what he says in the challenge: 'Some authors have suggested that even if agents lack options they nonetheless enjoy certain more general powers in virtue of which it can be just to blame them... [But] disjunctive approaches to the question of compatibilism - on which determinism would threaten some agentive modalities but not others - seem to be threatened by the present approach, on which the agentive modalities constitute an integrated whole that is not divisible in the way envisaged.' (Maier 2015: 133, emphasis added.) The fact that Maier thinks of the semicompatibilist as being sanguine about options in general being precluded by determinism reveals a misunderstanding of semicompatibilism on Maier's part. Maier's challenge relies on a certain picture of agency as requiring dual-powers (or contrastive options) that the semicompatibilist denies to be required for moral responsibility.

${ }^{17}$ Using 'option' for the notion developed here may not seem quite right, and perhaps it would be better to use 'specific ability' or 'power' instead. For 
having the specific ability (or power) to bring about A, but this does not require simultaneously having the specific ability (or power) to do something else instead (or even to refrain from Aing). We might call this account of options a unary notion. Having the option to A (in this sense) is non-contrastive; it does not imply that the agent has the ability to bring about A rather than some genuinely available alternative (though it may be done rather than some other merely epistemically possible alternative). To see whether $\mathrm{S}$ had the option of doing $\mathrm{A}$ when she did it, we need not look beyond the actual sequence that led to S's Aing. What should we look for in the actual sequence leading to S's Aing? It is open to the semicompatibilist to work this out however she prefers, but Fischer and Ravizza's notion of guidance control is a good place to start.

Recall (from section 2) that, in order for an agent to exercise guidance control in performing some action, that action must have issued from that agent's own moderately reasons-responsive mechanism. The conditions on guidance control preclude mere occurrences as well as actions resulting from extreme cases of coercion, manipulation, and the like from counting as under the agent's control, in the relevant sense. Mere occurrences are precluded because one cannot have guidance control over such things - agents exercise guidance control over actions. ${ }^{18}$ (Moreover, the moderate reasonsresponsiveness condition further restricts the class of actions over which an agent can have guidance control.) Problematic interference by other agents (such as by coercion and manipulation) is precluded

continuity with Maier's original project, I will continue to use 'option', but, since what is crucial is that the other agentive modalities (general abilities, skills, and potentialities) can be unified around some more basic notion, the structure of the account can be preserved no matter which notion we use. A potential objection is that it would be less plausible to take alternative notions (such as specific abilities or powers) to be primitive than it would be to take options as such, but, in my view, given the worries raised here about the ambiguity of 'option', this objection fails to get off the ground.

${ }^{18}$ As I mentioned in $\mathrm{n} .4$, the account of guidance control extends to omissions as well, though I am focusing on actions here. It is worth noting that the account allows for a distinction between omissions that are mere non-occurrences, on the one hand, and omissions that are under agents' guidance control, on the other, so nothing I say here depends on actions in particular. 
because, in order to have guidance control, the agent's mechanism must be her own. When an agent satisfies all of the conditions on guidance control, she exercises a higher degree of control over her behavior than she would if the behavior just happened to occur, or if it occurred as the result of interference by other agents. In cases involving mere occurrences and cases involving interference by other agents, it is not the case that there is nothing between the agent and the action (or occurrence). Whether it happened, in such cases, depended too much on luck or what other agents did for it to be true that the agent had the power to bring it about. But when an agent exercises guidance control over an action, she has a sufficiently high degree of control over it to count as having the power to bring it about.

With this semicompatibilist account of options, we can now construct a unified account of the same agentive modalities Maier considers (i.e., the ones we considered in section 3), namely: general abilities, potentialities, and skills. In fact, we can simply adopt Maier's characterization of each of these derivative agentive modalities, substituting the account of options I have just introduced for Maier's ambiguous understanding of options. I will then argue that none of these (including options themselves) would be precluded by determinism, so this (semicompatibilist) notion of 'option' is not unstable.

Let us begin with general abilities. On Maier's account:

Ability: S has the general ability to A iff S has, in a suitable proportion of similar circumstances, the option of Aing. (Maier 2015: 127)

As on Maier's account, having the option to A is neither necessary nor sufficient for having the general ability to A. The same is true if we substitute the new account of options for Maier's and leave everything else about the account of general abilities the same. Still, the account of general abilities depends on the account of options; to see whether S has the general ability to A, we look to see whether S has the option of Aing in a suitable proportion of similar circumstances. If I have the power to bring it about that I sink a free-throw in a suitable proportion of similar circumstances, then I have the general ability to sink the shot even if I am lacking a basketball right now (and thus lack the option of sinking it now).

Once we see that general abilities can be captured in terms of the new account of options, it is easy to see that there will be parallel 
accounts of potentialities and skills. Let us begin with Maier's account of the former:

Potentiality: S has the potentiality to A just in case there is a certain series of actions, each of which is an option for $S$, such that if $S$ were to perform those actions then $\mathrm{S}$ would have the general ability to A. (Maier 2015: 131)

As long as it is possible for there to be a series of actions that are options for me that leads to my having a general ability to A, then I have the potentiality to A. If I have the option of practicing shootings hoops today, the option of practicing tomorrow, and so on, and if this will lead to my having (in a few months or years, perhaps) the general ability to sink a free throw, then I have the potentiality to sink a free throw. Nothing about my semicompatibilist account of options precludes the possibility that such chains of actions are options for me.

Finally, recall Maier's account of skills:

Skill: $\mathrm{S}$ has the skill to A just in case $\mathrm{S}$ has the general ability to A partly in virtue of what she knows. (Maier 2015: 131)

On this account of skills, we need not reference options directly; rather, the account of skills is unified with the other agentive modalities insofar as it depends on the account of general abilities (which itself depends on options). Since we can give an account of general abilities that depends on the new account of options, and since this account of skills makes reference to general abilities, this account of skills can be integrated into the new account of options too.

We have seen that there is a non-contrastive account of options that is both friendly to semicompatibilism and that can unify the same agentive modalities as Maier's account does. The only issue left to address is whether or not any of the agentive modalities would be precluded by determinism. Recall that, according to semicompatibilism, the freedom required for moral responsibility is compatible with determinism even if the freedom to do otherwise is not. Maier claims that this view is committed to an unacceptable instability in the agentive modalities, since he thinks that the view is committed to claiming that determinism would preclude some but not all of the agentive modalities. But it is not the case that the semicompatibilist is 
committed to the claim that determinism would preclude some but not all of the agentive modalities. If S had the option of doing A and satisfied semicompatibilist conditions on freely Aing, then S had the option of Aing whether or not the world was deterministic. Given that such options are compatible with determinism, so too are general abilities (perhaps $\mathrm{S}$ exercised her general ability to A when she Aed in her deterministic world) and the other agentive modalities that depend on them. Sure, the semicompatibilist will say, determinism may well preclude alternative options, but the unified account of the agentive modalities presented here does not depend on alternative options (note in particular that the accounts of general abilities, potentialities, and skills make no reference to such options). Therefore, semicompatibilists can help themselves to a unified account of the agentive modalities while maintaining that it is possible for determinism to preclude the option of doing otherwise. ${ }^{19}$

\author{
Taylor W. Cyr \\ University of California, Riverside \\ Department of Philosophy, HMNSS 1604 \\ 900 University Avenue \\ Riverside, CA 92521, USA \\ taylor.w.cyr@gmail.com
}

\title{
References
}

Beebee, Helen and Mele, Alfred. 2002. Humean compatibilism. Mind 111: 201-223. Fara, Michael. 2008. Masked abilities and compatibilism. Mind 117: 844-865.

Fischer, John Martin. 1994. The Metaphysics of Free Will: An Essay on Control. Oxford: Blackwell.

Fischer, John Martin. 2006. My Way: Essays on Moral Responsibility. New York: Oxford University Press.

Fischer, John Martin and Ravizza, Mark. 1998. Responsibility and Control: A Theory of Moral Responsibility. Cambridge: Cambridge University Press.

${ }^{19}$ For comments on earlier versions of this paper, I am grateful to Zac Bachman, Dave Beglin, John Fischer, Meredith McFadden, Jonah Nagashima, Debbie Nelson, Michael Nelson, Jeremy Pober, Jared Smith. For helpful discussion of this paper, I am grateful to the participants of the 'II Blasco Disputatio: Does Free Will Require Alternative Possibilities?' conference at the University of Valencia, especially Nadine Elzein, Matthew Hart, Ferenc Huoranszki, Alex Kaiserman, Ben Matheson, Carlos Moya, Pablo Rychter, and Carolina Sartorio. 
Frankfurt, Harry. 1969. Alternate possibilities and moral responsibility. Journal of Philosophy 66: 829-839.

Maier, John. 2014. Abilities. In Stanford Encyclopedia of Philosophy (Fall 2014 Edition), ed. by Edward N. Zalta, URL $=<$ https://plato.stanford.edu/ archives/fall2014/entries/abilities/>.

Maier, John. 2015. The agentive modalities. Philosophy and Phenomenological Research 90: 113-134.

Smith, Michael. 2003. Rational capacities. In Weakness of Will and Practical Irrationality, ed. by Sarah Stroud and Christine Tappolet. Oxford: Clarendon Press.

van Inwagen, Peter. 1983. An Essay on Free Will. Oxford: Clarendon Press.

Vihvelin, Kadri. 2013. Causes, Laws, and Free Will: Why Determinism Doesn't Matter. New York: Oxford University Press.

Wallace, R. Jay. 1994. Responsibility and the Moral Sentiments. Cambridge, Mass.: Harvard University Press. 